\title{
Study of Education and Training Mechanism of China-ASEAN Cross-cultural Communication and Media Professionals
}

\author{
Naikao Wang \\ Xiamen University Tan Kah Kee College \\ Zhangzhou, Fujian, China 363105 \\ Macau university of science and technology \\ Macau, China 999078
}

\begin{abstract}
Whereas the higher education is an organic system composed of teaching, managing, learning processes and mutual promotion. Thereof, the education and training of professionals will subject to the direct limitation from the internal conditions of a college or university, and will be also indirectly affected by the external conditions existing in the whole educational system and our society. The mechanisms applicable for education and training, as discussed herein, are interpreted as the interactive relationships and functional integration among the factors essential for the operation of the education and training system adopted by a higher education institution. The Research Team had spent approximate 5 years in analyzing the factors essential for the education and training of professionals required by the cross-cultural communication and media industries within the China-ASEAN Region, including determining the interactive relationships among such factors, and had realized the functional integration of such factors, which will facilitate the quality education and training of such requisite professionals.
\end{abstract}

keywords-Education and Training Mechanism; ChinaASEAN; Cross-Cultural Communication; Media Professionals

\section{INTRODUCTION}

Whereas the higher education is an organic system composed of teaching, managing, learning processes and mutual promotion thereof, the education and training of professionals will subject to the direct limitation from the internal conditions of a college or university, and will be also indirectly affected by the external conditions existing in the whole educational system and our society. The mechanisms applicable for education and training, as discussed herein, are interpreted as the interactive relationships and functional integration among the factors essential for the operation of the education and training system adopted by a higher education institution.

The Research Team had spent approximate 5 years in analyzing the factors essential for the education and training of professionals required by the cross-cultural communication and media industries within the ChinaASEAN Region, including determining the interactive relationships among such factors, and had realized the functional integration of such factors, which will facilitate the quality education and training of such requisite professionals.

\section{SUPPly AND DEMAND ANALYSIS MECHANISM \\ APPLICABLE FOR CHINA-ASEAN CROSS-CULTURAL COMMUNICATION AND MEDIA PROFESSIONALS}

From the second half of the year 2010, the Research Team has completed a series of interviews and investigations successively in connection with all types of practices of the communication and media industry within the ChinaASEAN Free Trade Area (CAFTA), and has analyzed the supply and demand status of the professionals required by the cross-cultural communication and media industry within the China-ASEAN Region, with the results of such analyses, titled as "Cross-cultural Communication and Media Professionals Demand Analysis and Solutions within ChinaASEAN Region", published in the Business Culture (6th Issue, 2011).

As for the market, the ideal state is that the supply structure can perfectly match the demand structure of the professionals. But how can we make the professionals' supply more suitable to the market's demands and go closer to such ideal state? It's no doubt the forecast mechanism of professionals' supply and demand will play an important role.

According to the findings, i) a certain gap has been created in the demand of the cross-cultural communication and media professionals within the China-ASEAN Region, but has not develop into a strong growth; ii) the crosscultural communication activities, launched by the crosscultural communication and media industry within this Region, are not deep enough, and the personnel requirements of such activities can be satisfied by the supply of translators and interpreters, rather than industrial professionals; iii) no long-term mechanism has been established among the crosscultural communication and media activities launched within this Region, and most of such activities are short-term or occasional activities, which cannot provide stable employment. 
On the bases of interviews with the communication and media organizations operating in Nanning, Qinzhou, Beihai and other Chinese cities within the Pan-Beibu Gulf, and field researches in the representative nations of ASEAN, such as Thailand, Vietnam, etc., we found the following five types of communication and media professionals have relatively larger gaps between their supply and demand during the cross-cultural communication within the China-ASEAN Region.

\section{A. Cross-cultural Communication and Media Professionals-Specialists}

The environment of the ASEAN communication and media shall be understood first before any further cooperation with the ASEAN communication and media industry, so that we shall prepare an array of such communication and media professionals who will be the specialists having in-depth understandings of the ASEAN and the cross-cultural communication among China and ASEAN. Except for mastering extensive theories about communication and media, such specialists shall know very well about the local customs, practices, cultures and histories of all nations of ASEAN, and shall learn more about the history and current situation of the cultural communication among China and ASEAN.

\section{B. Cross-cultural Communication and Media Professionals-Generalists}

New media cooperation was the main subject discussed by the senior management from the communication and media industries of China and ASEAN, at the "4th ChinaASEAN Media Cooperation Seminar" held in Beijing from March 23 to March 25, 2010. As learned from this Seminar, China, Singapore, Philippines, Thailand and other nations having relatively developed communication and media industries had adopted new sophisticated media platforms, such as Internet, mobile communication, and some nations, such as Vietnam and Laos, are engaging in actively building the infrastructures for their new media. Media convergence will be the main trend all over the world, and the generalists, who are familiar with the operations and business of multiple media fields, including print, broadcasting, television, network and other media, will be the most demanded resources under the backgrounds of worldwide media convergence.

\section{Cross-cultural Communication and Media Professionals-Professional Managers}

At present, the increasing industrialization of the communication and media industry, the operations and businesses of communication and media organizations are not only related to the direction of public opinion or the public responsibilities, but also related to material interests. As reported, after several friendly negotiations, Guangxi Daily Media Group and Vietnam Quang Ninh Newspaper had entered into several agreements concerning their cooperation in news reporting, advertisement operation, print business, etc., with further cooperation under their schedules. The communication and media industry in China will play a key role throughout the regional cooperation between China and ASEAN on the bases of long history, rich culture, continuously evolving communication technologies, and the historical relationships built between China and ASEAN.

\section{Cross-cultural Communication and Media \\ Professionals-Senior Planners}

The China-ASEAN Free Trade Area (CAFTA) is now far from being widely known in China since its establishment, and the same situation can be found in Thailand and Vietnam according to our exchange students from this two nations. Many distorted reports by the western media about China can find their support receivers in Thailand. Under such backgrounds, it is suggested that the future media organizations shall be guided by such senior planners who have deep understandings, versatile abilities, various skills and creative ideas to deal with complicated situations, including but not limited to the domination of western media, the digitization and intellectualization.

\section{E. Cross-cultural Communication and Media Professionals-Skilled Persons}

The basic professional skills of news gathering and writing shall be always regarded as the core of the news reporting activity, and this principle is independent of the evolution of new media, the level of media convergence, the advancement of communication means or the evolvement of news presentation, since no news collecting or editing activity can be executed successfully without such basic professional skills. Therefore, the cross-cultural communication and media professionals who are familiar with the sophisticated media skills and techniques will be welcome by the industry. At present, Yunnan TV Station and Guangxi TV Station are competing to produce TV programs aiming at the ASEAN receivers, and they both need the skilled persons who are specialized in the cross-cultural communication with the ASEAN and have in-depth knowledge of the histories, cultures, applicable laws and available technologies of the ASEAN.

\section{EDUCATION AND TRAINING Plan UPGRADE}

MECHANISM APPLICABLE FOR CHINA-ASEAN CROSSCUltural COMMUNICATION AND MEDIA PROFESSIONALS

Based on the above circumstances, the Research Team believes that the Professionals' Supply and Demand Analysis Mechanism shall reflect the following features: i) such Demand shall be the future demands rather than any shortterm demands; 2) such Supply and Demand Analysis shall be executed based on the existing data to predict the development tendency in a long term; 3) such Supply and Demand Analysis Mechanism shall reflect the supply and demand situations in a dynamic mode.

Except for the Communication and Cooperation Joint Conferences and Media Cooperation Seminars launched by China and ASEAN, a professionals education and training mechanism should be established and completed on the bases of cooperation between the media industries of China and ASEAN, interaction and coordination among all 
interested parties, including the colleges, media organizations, governmental bodies, enterprises, culture and art industry's hatching matrix, etc.

\section{A. Provide Courses of ASEAN Minority Languages in Communication and Media Institutions}

Based on their unique cultural landscapes, many nations of ASEAN have their own unique languages. During the education and training of communication and media professionals, additional provision of a series of courses for ASEAN minority languages will help the student in understanding more about the culture in addition to learning a language, to improve their abilities to well serve the crosscultural cooperation with the ASEAN. At present, the ASEAN International Institute, Beihai College, Beihang University has established a complete set of course design system after 6 years of exploration.

\section{B. Increase Communications between the Communication and Media Institutions of China and ASEAN}

Through the China-ASEAN Education Information Network, launch and deepen a wide range of cooperation activities of education and research, among the colleges and scholars and concerning the fields most demanded by the local communication and media industry, in order to expand the communication of education, research and personnel, especially to provide valid information resources for the eager students from China and ASEAN. Meanwhile, attract more college teachers with rich educational backgrounds and professional accomplishments to participate in teaching exchange programs, to improve the global competitiveness of overall higher education within the Pan-Beibu Gulf and to provide labor and metal supports for the development of the CAFTA.

\section{Integrate the Communication and Media Education within the Pan-Beibu Gulf}

Since the cross-cultural communication and media education has more and higher requirements for the education and training environment, it is suggested to explore the feasibility of integration of the education within the Pan-Beibu Gulf, including mutual complementation and cooperation, integration of resources, mutual recognition of course credits, academic credentials and degrees, and expansion of student exchange and mobility, which will build a solid foundation for the growth of the professionals required by cross-cultural communication and media industry with the China-ASEAN Region. At present, Guangxi Province is actively implementing the "Double Hundred Thousand Student Mobility Plan", and fighting for realizing the "2020 Double Hundred Thousand Student Mobility Plan", namely the number of the students from ASEAN and the students to ASEAN will respectively reach one hundred thousand in 2020 .

\section{Build Regional Practice Platforms for Cross-cultural Communication and Media}

Corresponding practice platforms should be provided for the education and training of the professionals for the cross- cultural communication and media industry within ChinaASEAN Region. At present, such communication and media practice platforms are not enough, since only a few programs had been set by the television and broadcasting institutions in Guangxi and Yunnan Provinces, and the cross-national practices toward the ten nations of ASEAN are still at the exploration stage. From 2007, the Beihai College of Beihang University had dispatched approximate 50 current year's graduates in each summer vacation to the Thailand and Vietnam's exchange and practice projects, and these students would be accepted by certain communication and media colleges in ASEAN and then go to the television stations for practices together with the students from such colleges.

\section{E. Increase the Investment for the Research of ASEAN Communication and Media Industry}

At present, the cross-cultural communication has been incorporated by the Wuhan University, Renmin University of China and other higher institutions as an important part of journalism and communication studies. But, most of the researches of cross-cultural communication in China are aimed at the English-speaking countries in Europe and America, and only from the views and laws of publicity to foreign countries, cross-cultural communication, or cultural imperialism criticism, which are lack of special researches on the cross-cultural communication with the ASEAN countries speaking the minority languages.

\section{F. Build China-ASEAN Culture and Art Industry Matrix}

The culture and art industry utilizes creation, invention and innovation to realize the cultural contents and creative outcomes, and are characterized in the realization or consumption of intellectual properties. During the 11th Fiveyear Plan, the culture and art industries within the developed regions in China have grown rapidly. To build culture and art industry matrix in Guangxi and Yunnan Provinces will promote the cultural competiveness of the south-west region of China and will significantly facilitate the cultural communication between China and ASEAN.

\section{COLLEGE-ENTERPRISE COOPERATION AND} INTERACTION MECHANISM APPLICABLE FOR CHINA-ASEAN CROSS-CULTURAL COMMUNICATION AND MEDIA PROFESSIONALS

Communication and media industry is a promising industry, and many independent colleges offer news and communication courses according to the market requirements in this industry. But these colleges don't have enough teachers, teaching resources and practice places, which can provided by the Communication University of China, Wuhan University and other well-known news and communication colleges. At present, the Research Team has made a series explorations around the interaction mechanism, i.e. "outgoing" and "incoming" modes, between the news \& communication institutions and the communication \& media organizations, during the interviews, researches and practices executed with these communication and media organizations within the China-ASEAN Region. 


\section{A. Internal Resources Integration Strategy}

1) Leverage studios and design labs to facilitate cocreation of teachers and students: According to the analysis by Wang Rongsong, Head of Art Department, Beihai College, Beihang University, on the College's operation conditions, "with only more than 10 years of operation, the independent college has many natural deficiencies from its establishment due to the policy reasons, not enough trust among the three cooperators, and no public benefit or contribution systems, which are adopted by the funds in Europe and America to invest in the colleges for returning to the communities. The investor of an independent college in China always conservatively controls each penny of its investment, and adopts the enterprise operating ideas to manage the college. Accordingly, the expenditures for the software and hardware required by the labs are limited during the first five or ten years, to such a level of only providing requisite teaching and apartment building for the teachers and students. Just a little or no investment is planned for the investment in labs, public activity spaces, practice facilities, libraries, etc."

Under such backgrounds, the objective to train versatile professionals with high quality and capability will be only a slogan. For the purpose of improving such college running situations, the management from the Beihai College of Beihang University went to Shenzhen, Beihai, Nanning, Chengdu, Chongqing, Xizang, Beijing, Hong Kong and other places personally to find financing channels to actually provide the studios and design labs. The teachers of the College are required to lead the creation activities during spare time to increase the learning opportunities, passion and confidences of the students in their creation of art. In addition, the students of the College are required to participate more in the outcome exhibits of the teachers, to understand the flows of creation and marketing, and further to use the theories learned in classroom to the social practices.

After years of operation, the ASEAN International Institute and Art Institute of this College had created many bases for practices together with lot of relative enterprises, which will increase the practical abilities of the students. For example, the Nanzhugong Pearl Company, which is a subsidiary of Beihai Gofar Group, a listed company, had built close relationships with the Product Design Major and Digital Media Art Major of the Art Institute. Wang Shiqua, the President of this Company, had provided loving supports for the Art Institute and established a love fund to help poverty-stricken students by providing subsidies in each year. In addition Mr. Wang also gives lectures to the students about the knowledge and abilities essential for their future success, which greatly improves the learning and creating passions of the students.

2) Maximize the functions of the studios and art workshop: From its establishment, the Art Institute, Beihai College, Beihang University had tried hard to provide some teachers with a small shared workshop, used as a design room and studio for independent creation. Wang Rongsong from the Art Institute believed that "A doctor or master will lose his/her professional skills in a long time when acts as a teacher in a college after graduate if only teaching without any professional research activities. How will a teacher teach new knowledge to his / her students if he/she fails to make new achievements?"

During the interview, Wang Rongsong indicated emotionally that "a teacher with master or doctor degree shall fulfill his/her duties of teaching, but it's not enough. What his/her master or doctor degree will be used for except teaching? A teacher disliking his/her major would be regarded as no good product if examined according to the design and production integration systems adopted by the industrial enterprises. The Head of an institute of a college shall be a specialist in the relative fields with enough social influences and sufficient college education theories, or otherwise shall get far away from his post, for only regarding this post essential for education as a tool for earning money."

3) Design course contents according to social demands and industrial guidance of the nation: Art are extensively merged with the new media at now, the 21st century. Animation art and network communication, which are evolving along with the development of the computer application technologies, will be the majors provided in this College in the future. Computers have brought out a fundamental change to the "Great Art" during expanding its own possibilities.

Among the universities set up in the Beihai University City, the Art Institute of Beihai College, Beihang University is the only one providing the undergraduate courses for art, and therefore, will assume the tasks to cultivate and deliver professionals specialized in television and film media, broadcasting and hosting, art creation and design. For this reason, the Art Institute had held the first teacher's work exchange exhibit, titled as "Linkage and Improvement", at 2009, the year of establishment of the Art Institute, and lots of the local specialists, scholars and masters had been attracted to visit this exhibit. An exploration of the academic exchange and communication was started for the modern art and design within the Beibu Gulf by this exhibition, which also led the modern art within the Beibu Gulf to the world.

\section{B. External Resources Integration Strategy}

1) Cultural market predicts the demands of professionals by cross-cultural communication and media industry: Art education shall subject to the laws of the market economy system, namely all production serving the market, and shall serve the cultural market. As for how to serve the cultural market, the first step is to understand the cultural market. For dealing with the new situations of the cultural industry, the Academic Affairs Division of Beihai College, Beihang University had launched a series of investigation deep into the cultural enterprises in different geographic areas, at different economic levels, and having 
different cultural backgrounds, concerning their professionals demand status and structure, to explore the reasonable configuration of the professionals resources.

Zhang Liping, the Director of Beihai College; Liu Zhenghuan, the Head of ASEAN International Institute, and the representatives of teachers and students of the Art Institute of the Behai College, Beihang University had went to Nanning, Qinzhou, Beijing, Shenzhen, Guangzhou, Chongqing, Chengdu, Hong Kong and other places, together with the Research Team, for on-site investigation, which will facilitate the understanding of the situations of the relative industries, the adjustment of majors orderly and progressively, the perfection of the education and training mechanisms, and further the abilities to adapt to the new conditions of the industries emerged after the changes of the market structures.

2) Practice bases put the cross-cultural communication and media education into a new level: In an independent college, the main objective of education is to train and deliver versatile and applicative professionals with high practical abilities, and the practice segment shall be regarded as the key factor to examine, convert and develop the education theories. The art creation practice bases play an important role in the practice education processes of the art majors. The Beihai College of Beihang University had selectively built many practice bases based on the features of the art majors, together with the cultural enterprises and institutions.

The Art Institute of Beihai College, Beihang University had fully utilized the market advantages of the practice bases, and had made a series of constructive proposals about the existing theoretical teaching systems and the actual requirements of the current cultural industry according to the demands of the practice bases, to combine the education systems with the market, and ultimately to increase the applicability and practicability of the cultivated professionals. In addition, the establishment of such creation and practice bases had improved the brand influences of the Art Institute of Beihai College, Beihang University, to increase the confidences of the candidates and facilitate the performance of student recruiting tasks.

3) Deliver innovative and applicative professionals for the cross-cultural communication and media industry: Based on the operating features of "internationalization, versatility and applicability", the Beihai College of Beihang University intensified the objectives of training and providing innovative, versatile and applicative professionals.

a) Innovative: In recent years, the scale of art education is expanded, while the employment space of the professionals of art and design is shrunk. If only looking for the limited pure art creation opportunities, the art and design professionals will experience the most difficulties of employment. For this sake, Wang Rongsong starts the training from expanding the thoughts of the teachers, to require the teachers to understand the social demands at first, because the teachers are a bridge between the society and the students. After discussion, all teachers believe that it is essential to reinforce the innovative ability training of the students, such as adding design and software courses for students majoring in drawing, and adding basic art modeling for students majoring in art and design, which are only for the purposes of combining the great art with the computer technologies. During the extensive training of employment, the students are told to expand their thoughts about their employment, for their future jobs may be art and design management, art marketing and other jobs provided by the globalized cultural market, not only limited to art creation.

b) Applicative: The professionals shall fit in with the requirements of the industries and markets. With more attentions paid by the enterprises to the propaganda of their corporate cultures, a great number of propaganda and public relation professionals are demanded by the market, so that the graduates of culture and art can be trained with brand and image design or propaganda. The teachers having registered qualification certificates from the Beihai College of Beihang University can utilize their rich relationships with the government bodies, companies and enterprises to provide practice opportunities for the students to realize the purposes of serving enterprises and training students.

\section{EDUCATION AND TRAINING ENVIRONMENT CREATING MECHANISM APPLICABLE FOR CHINA-ASEAN CROSS-CULTURAL COMMUNICATION AND MEDIA PROFESSIONALS}

The professionals' cultivation cannot be separated from the education and training environment. With great emphasis on practice, the news and communication major shall update the course contents according to the development status of media and the education environment, to increase the adaptability of education to the market. The Research Team has explored the approaches to provide favorable education and training environment in the views of education resources and education measures:

- Actively and effectively integrate and utilize the national policy resources and environment.

- Actively and effectively integrate and utilize the local culture resources and environment.

- Actively and effectively integrate and utilize the college's internal resources and environment.

According to the strategic objectives of the 12th FiveYear Plan, the courses are planned and developed toward the pillar industries related to the industrial design, to push forward the establishment and development of future courses in the Art Institute. The operation of any school or college shall subject to the national policies, which shall be regarded as the guide for the future development. Accordingly, a school or college shall carefully study and understand the cultural policies and educational policies implemented by China to realize solid and powerful development.

At present, China strives to develop the CAFTA, and the colleges and universities in Guangxi Province shall set up 
their strategic tasks focusing on training and delivering the professionals for the cross-cultural communication and media industry in the China-ASEAN Region. For this consideration, the national policies and market laws shall be combined to create an integrated system of production, education, research and innovation, to integrate and utilize all resources, save operation cost, provide quality professionals, improve brand image and expand social influences.

\section{EDUCATION AND TRAINING PERFORMANCE} MONITORING MECHANISM APPLICABLE FOR CHINA-ASEAN CROSS-CULTURAL COMMUNICATION AND MEDIA PROFESSIONALS

The education and training performance can be monitored, examined and reflected from two aspects: the changes of external environments and the optimizing of internal resources, which can be broken down into different questions in an evaluation scale. A new employee of communication and media can make self-assessment conveniently by using this scale, and this will facilitate the communication and exchange of information between the colleges and the society.

For the purpose of satisfying the demands of the ChinaASEAN communication and media industry for all types of professionals as far as possible, we shall change the college operation ideas and adjust the market positioning reasonably based on the results of duly examination on the education and training performance, to create a positive cycle system for the education and training of professional, and to minimize the blindness in education and training. At present, we explore and adopt the following monitoring mechanisms:

- Monitor the education and training performance based on the feedback from the cooperative enterprises.

- Monitor the education and training performance based on the data of employment concerning occupation and location.

- Monitor the education and training performance based on the data in the self evaluation scale provided by students.

- Monitor the education and training performance based on the results of assessment by the experts on the professionals provided to the cross-cultural communication and media industry in the ChinaASEAN Region.

\section{CONCLUSION}

These four performance monitoring mechanisms are under their trial stages, and a summary report with academic paper will be delivered after January, 2013. According to the existing data, after the establishment of CAFTA, a favorable growth can be found in the cross-cultural communication between China and ASEAN, but the cooperation among the media organizations is expected to be reinforced and deepened. The demands by the cross-cultural communication and media industry in the China-ASEAN Region for the professionals will be increased step by step, and we will examine and upgrade such mechanisms in our future practices.

\section{ACKNOWLEDGEMENT}

This research was financially supported by the Youth Social Science Fund Project of Chinese Ministry of Education "Cross-strait cultural industry management personnel Comparative Research and innovation Taining mechanism"(Grant NO.15YJC760092) , and led by Wang Naikao; the science foundations of Guangxi Province and Fujian Province, and this Article is one of the phased deliverables of the Guangxi Province Key Education Reformation Project, titled as "Study of Education and Training Mechanism of China-ASEAN Cross-Cultural Communication and Media Professionals", numbered as 2011JGZ064 and led by Wang Naikao; and the Fujuan Educational Bureau Social Science Project, titled as "Fujian Independent College's Strategies and Practices of Brand Communication Integration", numbered as JB12396S and led by Wang Naikao.

\section{REFERENCES}

[1] Li Yiping, Perspective of ASEAN Media, Yunnan People's Publishing House, 2004.

[2] Wu Ying, International Communication of Culture -- Theories and Practices, Shanghai Jiao Tong University Press, 2009.

[3] Wang Naikao, Necessity of Training China-ASEAN Cross-cultural Communication and Media Professionals, J. Journalism \& Communication, 12 (2011)

[4] Wang Naikao, Zhang Liping, China-ASEAN Cross-cultural Communication and Media Professionals Demand Analysis and Solutions, J. Business Culture, 6(2011).

[5] Wang Naikao, Exploration of Education and Training of ChinaASEAN Cross-cultural Communication and Media Professionals, J. Journalism \& Communication,3(2012).

[6] Wang Naikao, Study of Cooperation between Media and Journalism \& Communication Major, J. Today's Mass Media, 5(2012). 